\title{
BMJ Open Prevalence of depression and anxiety symptoms and their determinant factors among patients with cancer in southern Ethiopia: a cross-sectional study
}

To cite: Ayalew M, Deribe B Duko B, et al. Prevalence of depression and anxiety symptoms and their determinant factors among patients with cancer in southern Ethiopia: a cross-sectional study. BMJ Open 2022;12:e051317. doi:10.1136/ bmjopen-2021-051317

- Prepublication history for this paper is available online. To view these files, please visit the journal online (http://dx.doi org/10.1136/bmjopen-2021051317).

Received 17 March 2021 Accepted 22 December 2021

Check for updates

(c) Author(s) (or their employer(s)) 2022. Re-use permitted under CC BY-NC. No commercial re-use. See rights and permissions. Published by BMJ.

For numbered affiliations see end of article.

Correspondence to Mohammed Ayalew; mameayale@gmail.com

\section{ABSTRACT}

Objective The study was aimed to assess the prevalence of depression and anxiety symptoms and their determinant factors among patients with cancer attending follow-up at Hawassa University Comprehensive Specialized Hospital cancer treatment centre, Ethiopia.

Design Institution-based cross-sectional study design was implemented.

Setting Patients with cancer at Hawassa University Comprehensive Specialized Hospital cancer treatment centre from October 2019 to December 2019.

Participants Randomly selected 415 patients with cancer who had follow-up at cancer treatment centre.

Main outcome measures Anxiety and depression symptoms were assessed using Hospital Anxiety and Depression Scale.

Result The prevalence rates of depression and anxiety symptoms were found to be 244 (58.8\%) and 249 (60.0\%), respectively. Older age ( $>50$ years) (AOR (adjusted $\mathrm{OR})=2.24,95 \% \mathrm{Cl}=1.14$ to 4.40 ), being unemployed (AOR=1.96, 95\% $\mathrm{Cl}=1.08$ to 3.56), advanced stage of cancer such as stage III (AOR=5.37, 95\% $\mathrm{Cl}=1.34$ to 21.45) and stage IV ( $\mathrm{AOR}=4.55,95 \% \mathrm{Cl}=1.12$ to 18.44 ), comorbid psychotic symptoms ( $\mathrm{AOR}=1.67,95 \% \mathrm{Cl}=1.07$ to 2.61 ) and eating problem in the past 2 weeks (AOR=6.16, 95\% $\mathrm{Cl}=1.98$ to 19.11) were independent factors significantly associated with depressive symptoms. In addition, cancer stage such as stage $\|$ ( $A O R=3.92,95 \% \mathrm{Cl}=1.07$ to 14.36) and stage IV ( $\mathrm{AOR}=5.04,95 \% \mathrm{Cl}=1.44$ to 17.59$)$ and comorbid psychotic symptoms ( $\mathrm{AOR}=1.73,95 \% \mathrm{Cl}=1.12$ to 2.66) were significantly associated with anxiety symptoms. Conclusion Depression and anxiety symptoms among patients with cancer were considerably high. Age, occupation, cancer stage, comorbid psychotic symptoms and eating problem were determinant factors of depressive symptoms among patients with cancer. Moreover, cancer stage and comorbid psychosis were determinants of anxiety symptoms. Healthcare professionals working in the oncology unity need to conduct routine screening and treatment of depression and anxiety symptoms for patients with cancer.

\section{INTRODUCTION}

Nowadays, cancer is one of the world's most serious public health agendas and the second
Strengths and limitations of this study

- We use standardised questionnaires to assess dependent variables and this study also provides valuable baseline data in the area.

- The study is cross-sectional, and direction of association between depression and anxiety and related factors could not be established.

- Some of the physical symptoms due to the cancer itself or its treatment may have an impact on the magnitude of depression or anxiety.

- Risk of biased responses such as social desirability bias by which patients either exaggerate or minimise the symptoms of depression and anxiety for some reason.

leading cause of death. ${ }^{1}$ In 2018, the WHO estimated that cancer caused approximately 18 million new cases and 9.6 million deaths worldwide. ${ }^{2}$ Breast, lung, colorectal, prostate and skin cancer are the most common causes of cancer death. According to their diagnosis, patients with cancer undergo unique treatment modalities, such as surgery, radiation and chemotherapy. ${ }^{3}$

When a person is diagnosed with cancer, they are more likely to experience adverse mental health outcomes such as depression and anxiety. ${ }^{45}$ Depression and anxiety are the two most prevalent and debilitating neuropsychiatric disorders caused by physical illnesses like cancer. ${ }^{6}$ Depression and anxiety are both psychological and physiological disturbances characterised by a set of physical, emotional and behavioural elements.

Patients with cancer initially experience shock or denial, followed by emotional chaos, nervousness, lack of concentration, difficulty falling asleep, loss of appetite, irritability and intrusive thoughts about the future. ${ }^{8}$ Anxiety and depression are frequent emotional reactions to 
a cancer diagnosis and are deemed normal. Some patients, however, have an overpowering reaction that interferes with their everyday activities, ${ }^{9}$ and high levels of signs and symptoms can last for weeks, months or even years. ${ }^{10}$ These are due to perceived threats such as loss of body functions, changes in appearance, disruption of family and life plans, death, diminished quality of life, recurrence or progression of the disease, and the occurrence of unpleasant symptoms such as pain, nausea, and fatigue. ${ }^{811}$

According to a recent study conducted in the UK, depression and anxiety affect approximately $20 \%$ and $10 \%$ of patients with cancer, respectively, compared with $5 \%$ and $7 \%$ of the general population. ${ }^{12}$ Furthermore, depression is the most studied psychiatric disorder in patients with cancer, with prevalence ranging from $3 \%$ to $58 \% .{ }^{13-16}$ However, according to a previous study, nearly three-fourths $(73 \%)$ of these depressed patients with cancer do not receive appropriate psychiatric intervention, and only $5 \%$ seek mental health professional help. ${ }^{17}$ Early detection and treatment of depression and anxiety in patients with cancer, on the other hand, results in a reduction in disease progression, increased survival rates, lower medical costs and improved quality of life. ${ }^{18} 19$

Almost two-thirds of patients with cancer have significant levels of anxiety and depression, which impair individuals' quality of life $^{20}$ and increase their risk of suicide ${ }^{21}$ Furthermore, untreated depression and anxiety have significant negative consequences, including altered treatment decision-making, ${ }^{22}$ non-compliance with treatment, extended recovery times and ${ }^{10}$ increased intensity of pain. ${ }^{23}$ Depression has been shown to be underdiagnosed and under-recognised in clinical practice, ${ }^{24}$ owing to the complex nature and inter-relationship between cancer and depression in patients with cancer. ${ }^{25} 26$

Despite the fact that depression and anxiety are the most common complications in patients with cancer, they are frequently overlooked. ${ }^{27}$ Furthermore, the psychosocial requirements of patients with cancer, whether they have a mental illness history or not, are frequently overlooked during cancer therapy, which is primarily focused on addressing somatic symptoms and side effects. Earlier detection and improved treatment of cancer make people live longer with cancer. ${ }^{28}$ As far as our knowledge is concerned, there is a scarcity of explicit data showing evidence in the Ethiopian context in general, and in the study area in particular, regarding the mental health problems of people living with cancer. Therefore, the objective of this study was to assess the prevalence of depression and anxiety symptoms in Ethiopian patients with cancer, as well as to identify various influencing factors for depression and anxiety symptoms.

\section{METHODS AND MATERIALS}

\section{Study design and setting}

From October to December 2019, an institution-based cross-sectional study design was used at Hawassa University Comprehensive Specialized Hospital (HUCSH) cancer treatment centre. The hospital is the only one in the region that provides cancer care, and it is now constructing one of Ethiopia's largest cancer treatment centres.

\section{Study subjects}

Randomly selected patients diagnosed with cancer and who have follow-up at outpatient department of oncology unit.

\section{Inclusion and exclusion criteria}

Those adult ( $\geq 18$ years) patients diagnosed with any form or type of cancer were included in the study. However, patients who are unable to give proper information or critically ill patients at the time of interview and those with a history of mental disorder were excluded from the study.

\section{Sampling and data collection}

The required sample size was determined using single population proportion formula:

$\left(\mathrm{Z}_{\alpha / 2}\right)^{2} \times \mathrm{p} \times(1-\mathrm{p}) / \mathrm{d}^{2}$, where $\mathrm{n}$ is the sample size, $\mathrm{z}$ is the standard normal score set at $1.96, \mathrm{~d}$ is the desired degree of accuracy and $\mathrm{p}$ is the estimated proportion of the target population. By taking $\mathrm{p}=50 \%, \mathrm{Z}_{\alpha / 2}=1.96$ and $\mathrm{w}=5 \%$, the computed sample size was 384 ; and by taking $10 \%$ non-response rate, the total sample size computed was 422. Systematic random sampling technique was used for this study. Patients with cancer who were visiting HUCSH cancer clinic during the study period and who fulfilled the inclusion criteria were included in the study until the final study sample size was reached.

Data were collected by three oncology nurses who had received 2 days of intense training on data collection methodologies and instruments. In 5\% of the sample, a pretest was conducted to identify potential problems with the data collecting tools, as well as to assess the consistency of the questionnaires and the performance of the data collectors. During data collection, supervision was maintained, and each questionnaire was checked for completeness on a daily basis by the supervisor.

\section{Variables and measurements}

Data were collected by using interviewer-administered structured questionnaire. It consists of independent variables such as sociodemographic characters, clinical related factors of patients and healthy lifestyle-related factors (nutritional status, body mass index (BMI), substance use, etc), and dependent variables (depression and anxiety). The questionnaire is developed in English and translated to local language (Amharic), and the Amharic version was used to collect the data.

The Hospital Anxiety and Depression Scale (HADS) was used to assess the dependent variables anxiety and depression. It consists of two subscales, anxiety and depression. ${ }^{29}$ The HADS consists of 14 items: 7 items for the anxiety subscale (HADS anxiety) and 7 for the depression subscale (HADS depression). Each item is scored on a response scale with four alternatives ranging between 0 and $3 .^{30}$ Item scores were summed to provide subscaled 
scores of anxiety and depression, ranging between 0 and 21, and total summed score ranging from 0 to 42. A higher score represents higher symptoms of anxiety or depression. ${ }^{31}$ Recommended cut-off scores are 8-10 for doubtful cases and $\geq 11$ for definite cases. ${ }^{29}$

The Eastern Cooperative Oncology Group (ECOG) Scale was used to measure the patient's performance status. This scale captures patient-derived functional status data on a scale of $0-4$. An ECOG score of 2-4 indicates a poor performance status, whereas a score of $0-1$ indicates a good performance status. Researchers have confirmed the validity of the ECOG Chinese version in assessing the performance status of Chinese patients with cancer. $^{32}$

The five-item Psychosis Screening Questionnaire (PSQ-5) was used to assess the presence of psychotic symptoms in the past year. ${ }^{33}$ The PSQ has five probe questions enquiring about mania, thought insertion, paranoia, strange experiences and hallucinations. Individuals with psychosis were those who answered yes to one or more psychotic symptoms on the PSQ ${ }^{34}$

To assess suicide behaviour, a four-item Suicidal Behaviour Questionnaire Revised (SBQ-R) was used. SBQ-R item 1 taps into lifetime suicidal ideation and attempt; item 2 assesses the frequency of suicidal ideation over the past 12 months; item 3 taps into the threat of suicidal behaviour and item 4 evaluates self-reported likelihood of suicidal behaviour. The sensitivity was $80 \%$ and specificity $91 \%$, with a score of 3-18 and cut-off point of $\geq 8$ for adult clinical population. ${ }^{35}$

Level of social support among patients with cancer was assessed using the three-item Oslo Social Support Scale and the scores range from 3 to 14 . It is categorised as poor, ${ }^{3-8}$ moderate ${ }^{9-11}$ and strong ${ }^{12-14}$ social support. ${ }^{36}$

Intensity of cancer pain was assessed using universal pain screening with a 0-10 pain intensity on the Numerical Rating Scale. Pain intensity was categorised as 'none' for a score of 0 , 'mild' for a score of 1-3, 'moderate' for a score of 4-6 and 'severe' for a score of 7-10 as reported by the patient. ${ }^{3738}$

Nutritional status was assessed using Mini-Nutritional Assessment Short-Form Scale. It is a screening tool to assess malnutrition or risk of malnutrition and consists of six items related to appetite, loss of weight, mobility, mental distress or acute disease, presence of cognitive impairment and BMI. ${ }^{39}$ A score of $12-14$ is considered as normal nutritional status and a score of $\leq 11$ indicates malnutrition or risk of malnutrition. ${ }^{40}$

\section{Data processing and analysis}

Data were entered to EpiData V.3.1 and exported to SPSS V.24 for Windows for analysis. Descriptive statistics were used to identify distributions of sociodemographic characteristics of study participants. Prevalence of anxiety and depression symptoms was calculated by summing up the HADS and dichotomising the total score into positive or negative for presence of depression or anxiety. Both bivariate and multivariable logistic regression analyses with $95 \%$ CI were used to see the association between independent and outcome variables. During the bivariate analyses, variables with a $p$ value less than 0.20 were entered into a multivariable logistic regression model using an enter method. Finally, those variables which showed statistical significance at $\mathrm{p}<0.05$ and $95 \% \mathrm{CI}$ in the final model were reported as independently associated with anxiety and depression. The model fitness test was conducted using the Hosmer and Lemeshow goodnessof-fit test.

\section{Patient and public involvement}

Patients and the public were not involved in this study, including the recruitment, data collection, analysis, interpretation and dissemination of the results.

\section{RESULT}

\section{Sociodemographic characteristics of the patients}

A total of 423 patients with cancer were targeted for the study, with 415 participating at a response rate of $98.3 \%$. The mean age of patients is 42.51 ( $\mathrm{SD} \pm 14.24$ ) years. The study participants were dominantly Protestant (146, $35.2 \%)$ by religion followed by Orthodox Christianity $(136,32.8 \%)$. The majority of study subjects $(339,81.7 \%)$ were married. A total of $160(38.6 \%)$ participants were unable to read and write, $346(83.4 \%)$ were unemployed and nearly one-third $(133,32.0 \%)$ were rural residents (table 1).

\section{Clinical characteristics of the patients}

The median time since cancer diagnosis and time to begin treatment are 5 and 3 months, respectively. More than one-third $(148,35.7 \%)$ have breast cancer followed by gastrointestinal-related cancer (84, 20.2\%); 173 (41.7\%) had stage III cancer, $180(43.4 \%)$ had moderate level of pain, $66(64.1 \%)$ of the patients were on chemotherapy and nearly half $(195,47.0 \%)$ had moderate social support (table 2).

\section{Prevalence of depression and anxiety symptoms}

The prevalence rates of depression and anxiety symptoms among patients with cancer were found to be $58.8 \%$ $(\mathrm{n}=244)$ and $60 \%(\mathrm{n}=249)$, respectively, in our study as indicated in figure 1 .

\section{Independent predictors of depression and anxiety among patients with cancer}

Among many variables included in the bivariate analysis, those variables (occupation, type of cancer, cancer stage, intensity of pain, type of cancer treatment, taking of corticosteroid medication, comorbid medical illness, anxiety, psychosis, malnutrition, eating problems, age and BMI) with $\mathrm{p}<0.25$ were included in the multivariable logistic regression analysis. Only five variables, that is, age $>50$ years (adjusted OR (AOR) $=2.24,95 \% \mathrm{CI}=1.14$ to 4.40 ), being unemployed ( $\mathrm{AOR}=1.96,95 \% \mathrm{CI}=1.08$ to 3.56$)$, cancer stage (stage III (AOR $=5.37,95 \% \mathrm{CI}=1.34$ to 21.45$)$ and stage IV $(\mathrm{AOR}=4.55,95 \% \mathrm{CI}=1.12$ to 18.44$)$ ), comorbid 
Table 1 Sociodemographic characteristics of patients with cancer at HUCSH, $2019(n=415)$

\begin{tabular}{|c|c|c|c|}
\hline Variables & Category & Frequency & Percentage \\
\hline Mean $( \pm S D)$ age in years & & $42.51( \pm 14.24)$ & \\
\hline Gender & Male & 144 & 34.7 \\
\hline \multirow[t]{3}{*}{ Religion } & Protestant & 146 & 35.2 \\
\hline & Orthodox & 136 & 32.8 \\
\hline & Other & 8 & 1.9 \\
\hline \multirow[t]{4}{*}{ Educational status } & Unable to read and write & 160 & 38.6 \\
\hline & Primary education & 125 & 30.1 \\
\hline & Secondary education & 79 & 19.0 \\
\hline & College and above & 51 & 12.3 \\
\hline \multirow{2}{*}{ Marital status } & Widowed & 28 & 6.7 \\
\hline & Divorced & 4 & 1 \\
\hline \multirow[t]{2}{*}{ Occupation } & Employed & 69 & 16.6 \\
\hline & Unemployed & 346 & 83.4 \\
\hline \multirow[t]{2}{*}{ Residence } & Urban & 282 & 68.0 \\
\hline & Rural & 133 & 32.0 \\
\hline
\end{tabular}

HUCSH, Hawassa University Comprehensive Specialized Hospital.

psychotic symptoms $(\mathrm{AOR}=1.67,95 \% \mathrm{CI}=1.07$ to 2.61$)$ and eating problem in the past 2 weeks $(\mathrm{AOR}=6.16,95 \%$ $\mathrm{CI}=1.98$ to 19.11) were independent factors of depression symptoms among patients with cancer (table 3 ).

Therefore, older patients ( $>50$ years) were two times more likely to be affected by depression than younger age groups ( $<30$ years), and unemployed patients were nearly two times more likely to be affected by depression than those who were employed. Those patients with advanced stage of cancer (stage III were 5.3 times and stage IV were 4.5 times) were more likely to develop depression than those who had stage I cancer. Furthermore, patients with cancer with comorbid psychotic symptoms and eating problems in the past 2 weeks were 1.6 and 6.1 times more likely to be affected by depression than their counterparts.

In addition, patients with stage II (AOR $=3.92,95 \%$ $\mathrm{CI}=1.07$ to 14.36$)$ and $\mathrm{IV}(\mathrm{AOR}=5.04,95 \% \mathrm{CI}=1.44$ to 17.59) cancer are four and five times more likely to be affected by anxiety, respectively, than those patients with stage I cancer. Patients with cancer with comorbid psychosis (AOR=1.73, 95\% CI=1.12 to 2.66) were 1.7 times more likely to be affected by anxiety as shown in table 4 .

\section{DISCUSSION}

The primary aim of this study was to look into the prevalence of anxiety and depression symptomatology among Ethiopian patients with cancer, as well as the risk factors associated with them. In our study, the prevalence of depression symptoms among patients with cancer was found to be $58.8 \%$ (95\% CI=54.0\% to $63.6 \%$ ). This finding is similar to the results of a study on patients with cancer conducted in Gondar $(58.4 \%),{ }^{41}$ Pakistan $(61.6 \%)^{42}$ and the pooled prevalence $(54.9 \%)$ in China. ${ }^{10}$ However, compared with some previous literature, the reported rates of depression in our study were slightly lower than the studies in Bahir Dar and Gondar, Ethiopia $(70.8 \%){ }^{43}$ Rwanda $(67.7 \%)^{27}$ and China $(66.7 \%) .{ }^{44}$ On the other hand, our finding is higher than studies by Naser et al, in Jordan $(23.4 \%) .^{45}$ This disparity might be attributed to differences in the study populations in terms of cancer types, screening tools used, or other sociodemographic variations and severity of depression taken into account.

Regarding the prevalence of anxiety symptoms in Ethiopian patients with cancer, our finding (60\%, 95\% $\mathrm{CI}=55.4 \%$ to $64.6 \%$ ) is higher than studies in Gondar $(51 \%),{ }^{41}$ China $(43.5 \%),{ }^{46}$ Iran $(43.2 \%),{ }^{47}$ Jordan $(19.9 \%),{ }^{44}$ Rwanda $(52.1 \%)^{27}$ and Sudan $(26.7 \%){ }^{48}$ However, the results presented in this study confirm that patients with cancer suffer from psychological or psychiatric complications. This variation could be due to differences in participants' place of residence, their demographic characteristics, methodological differences of the studies and sample size.

Similar to previous studies, ${ }^{49}$ the finding of this study showed that older age groups were more prone to 
Table 2 Clinical characteristics of patients with cancer at HUCSH, $2019(n=415)$

\begin{tabular}{|c|c|c|c|}
\hline Variables & Category & Frequency & Percentage \\
\hline \multirow[t]{7}{*}{ Type of cancer } & Breast & 148 & 35.7 \\
\hline & Cervical & 7 & 1.7 \\
\hline & Genitourinary & 31 & 7.5 \\
\hline & Gastrointestinal & 84 & 20.2 \\
\hline & Lung & 13 & 3.1 \\
\hline & Lymphoma & 51 & 12.3 \\
\hline & Other & 81 & 19.5 \\
\hline \multirow[t]{5}{*}{ WHO cancer staging (I-IV) } & 1 & 15 & 3.6 \\
\hline & $\|$ & 54 & 13.0 \\
\hline & III & 173 & 41.7 \\
\hline & IV & 129 & 31.1 \\
\hline & Unknown & 44 & 10.6 \\
\hline \multirow[t]{4}{*}{ Intensity of pain } & None & 48 & 16.6 \\
\hline & Mild & 58 & 14.0 \\
\hline & Moderate & 180 & 43.4 \\
\hline & Severe & 129 & 31.0 \\
\hline \multirow[t]{3}{*}{ Type of treatment } & Chemotherapy only & 266 & 64.1 \\
\hline & Surgery only & 15 & 3.6 \\
\hline & Combination therapy & 134 & 32.3 \\
\hline \multirow[t]{2}{*}{ Take corticosteroid medication } & Yes & 350 & 84.3 \\
\hline & No & 65 & 15.7 \\
\hline \multirow[t]{2}{*}{ Comorbid chronic medical illness } & Yes & 65 & 15.7 \\
\hline & No & 350 & 84.3 \\
\hline \multirow[t]{2}{*}{ Use of substance over the last 3 months } & Yes & 17 & 4.1 \\
\hline & No & 398 & 95.9 \\
\hline \multirow[t]{2}{*}{ Performance status (ECOG Scale) } & Good & 364 & 87.7 \\
\hline & Poor & 51 & 12.3 \\
\hline \multirow[t]{3}{*}{ Duration of illness } & $<12$ months & 355 & 85.5 \\
\hline & 13-36 months & 48 & 11.6 \\
\hline & $>37$ months & 12 & 2.9 \\
\hline \multirow[t]{3}{*}{ Duration of treatment } & $<12$ months & 375 & 90.4 \\
\hline & 13-36 months & 31 & 7.5 \\
\hline & $>37$ months & 9 & 2.2 \\
\hline \multirow[t]{2}{*}{ Malnutrition } & Yes & 303 & 27.0 \\
\hline & No & 112 & 73.0 \\
\hline \multirow[t]{4}{*}{ BMI } & Underweight & 71 & 17.1 \\
\hline & Normal weight & 282 & 68.0 \\
\hline & Overweight & 46 & 11.1 \\
\hline & Obese & 16 & 3.9 \\
\hline \multirow[t]{2}{*}{ Eating problem } & Yes & 393 & 94.7 \\
\hline & No & 22 & 5.3 \\
\hline \multirow[t]{2}{*}{ Psychosis } & Yes & 236 & 56.9 \\
\hline & No & 179 & 43.1 \\
\hline \multirow[t]{2}{*}{ Suicide behaviour } & Yes & 32 & 7.7 \\
\hline & No & 383 & 92.3 \\
\hline
\end{tabular}


Table 2 Continued

\begin{tabular}{llrr}
\hline Variables & Category & Frequency & Percentage \\
\hline Social support & Poor & 124 & 29.9 \\
& Moderate & 195 & 47.0 \\
& Strong & 96 & 23.1 \\
\hline
\end{tabular}

BMI, body mass index; ECOG, Eastern Cooperative Oncology Group; HUCSH, Hawassa University Comprehensive Specialized Hospital.

depression. Older patients experience longer disease duration, a higher risk of cancer metastases and more disabilities, all of which contribute to depression. ${ }^{50}$ Another reason could be that older patients have difficulty asking for assistance and communicating with others. Furthermore, worrying about excessive treatment costs and family financial difficulties may be causes of psychological distress.

Findings from previous studies indicated that depressive symptoms are more common in unemployed individuals. ${ }^{51}$ Similarly, our result underlined that unemployed patients with cancer are more likely to be affected by depression than their counterparts. Hence, unemployment in combination with cancer exerts overwhelming physical and psychological strain such as depression in an individual. ${ }^{52}$ On the other hand, a substantial number of patients with cancer suffer from psychosomatic and social problems such as tiredness, pain, cognitive deficits, anxiety and depression. ${ }^{53}$ These enduring physical and psychological effects of cancer or its treatment may be a reason for social and occupational dysfunction including the withholding of employment. ${ }^{54}$

High magnitude of anxiety and depression can be related to end-stage cancer. ${ }^{50}$ In line with this, our study also showed that patients with cancer with advanced disease stages are vulnerable to anxiety. This might be related to the higher levels of physical debilitation and advanced illnesses. ${ }^{55}$ Prevalence of psychiatric disorders mostly varies at different stages of cancer. Despite the fact that adjustment disorders with depressed or anxious moods are more frequent at the early stage of the disease, severe psychiatric complications such as

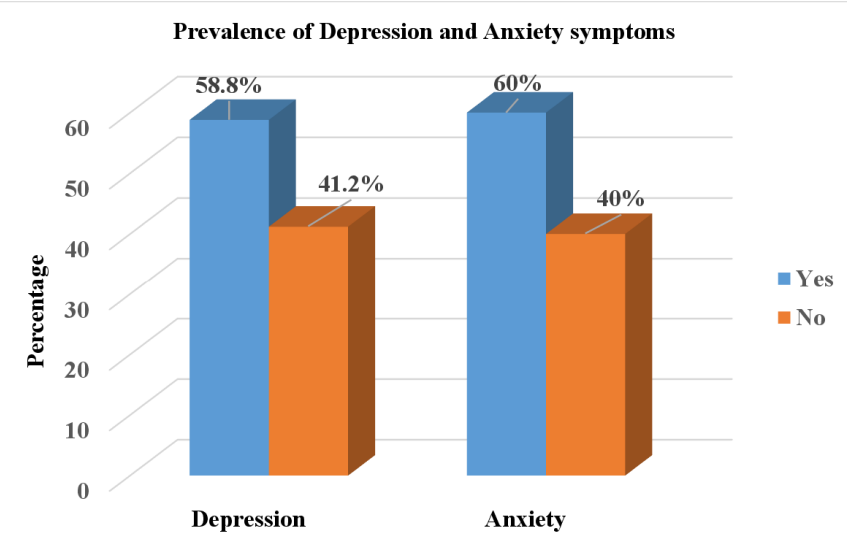

Figure 1 Prevalence of depression and anxiety symptoms among patients with cancer attending HUCSH, southern Ethiopia, 2019 ( $n=415)$. HUCSH, Hawassa University Comprehensive Specialized Hospital. very severe anxiety and major depression are more common in late stages of cancer. ${ }^{56}$ As a result, patients with late-stage cancer are more likely to be subjected to high doses of chemotherapy or any other anti-cancer treatment, resulting in a loss of appetite. Chemotherapy has been reported to cause severe sadness, anger, anorexia and anxiety in patients with cancer, despite the fact that it frequently enhances survival rates. ${ }^{55}$

Even though depression and psychosis are considered as a separate concept, this study showed that patients with cancer with comorbid psychotic symptoms are more prone to depression. Clinically, this suggests diagnoses such as schizoaffective or mood disorders with psychotic features, in which depressive and psychotic symptoms co-occur. The comorbidity between depression and psychotic disorders is very high, too. ${ }^{57}$ Experiencing psychotic symptoms such as hallucination and delusion induces feelings of fear, hopelessness and helplessness which ends up with depression. ${ }^{58}$ Conversely, depression could have an impact on psychotic symptoms by provoking negative appraisal of external stimuli, consequently increasing psychotic symptoms. ${ }^{59}$ Also, psychosis and depression may result in shared liability that leads both to exist on the same continuum. ${ }^{60}$ However, further research is needed to clarify this complex relationship.

We also found out that depression is more experienced by patients with eating problems such as nausea and vomiting. This is because patients may feel nauseous or vomit the week or day before treatment, as they approach the clinic, or even just thinking about chemotherapy. ${ }^{8}$ Moreover, exposure to high doses of chemotherapeutic and steroid agents induces depressive symptoms such as reduced appetite caused by gastrointestinal side effects like nausea and vomiting. ${ }^{61} 62$

Symptoms and syndromes of anxiety are present in the majority of patients with psychotic illness, ${ }^{63}$ and psychotic symptoms are also often reported in patients with affective disorders like anxiety disorders. ${ }^{64}$ Similar to these findings, in our study, patients with comorbid psychotic symptoms are more likely to develop anxiety than their counterparts. As a result, affective dysregulation (anxiety) and reality distortion coexisted within the range of subclinical and clinical expression. ${ }^{59}$

Despite providing valuable baseline data, this study has also some limitations encountered. The study is cross-sectional, and direction of association between depression and anxiety and related factors could not be established. Some of the physical symptoms, which are part of the HADS symptoms list, may have been due to the cancer itself or its treatment rather than due to depression or anxiety. These may have 
Table 3 Bivariate and multivariable regression analyses on depressive symptoms and associated factors among patients with cancer at HUCSH, $2019(n=415)$

\begin{tabular}{|c|c|c|c|c|c|c|c|}
\hline \multirow[b]{3}{*}{ Variables } & \multirow[b]{3}{*}{ Category } & \multicolumn{4}{|c|}{ Depression symptoms } & \multirow[b]{3}{*}{ COR $(95 \% \mathrm{Cl})$} & \multirow[b]{3}{*}{ AOR $(95 \% \mathrm{Cl})$} \\
\hline & & \multicolumn{2}{|l|}{ Yes } & \multicolumn{2}{|l|}{ No } & & \\
\hline & & $\mathbf{N}$ & $\%$ & $\mathbf{N}$ & $\%$ & & \\
\hline \multirow[t]{3}{*}{ Age (years) } & $<30$ & 45 & 51.1 & 43 & 48.9 & 1 & 1 \\
\hline & $31-50$ & 130 & 56.8 & 99 & 43.2 & 1.19 (0.73 to 1.96$)$ & 1.02 (0.58 to 1.77$)$ \\
\hline & $>50$ & 69 & 70.4 & 29 & 29.6 & $2.66(1.46 \text { to } 4.84)^{\star \star \star}$ & $2.24(1.14 \text { to } 4.40)^{*}$ \\
\hline \multirow[t]{2}{*}{ Occupation } & Employed & 34 & 49.3 & 35 & 50.7 & 1 & 1 \\
\hline & Unemployed & 210 & 60.7 & 136 & 39.3 & $1.59(0.95 \text { to } 2.67)^{\star \star \star}$ & $1.96(1.08 \text { to } 3.56)^{*}$ \\
\hline \multirow[t]{7}{*}{ Type of cancer } & Breast & 93 & 62.8 & 55 & 37.2 & 1 & 1 \\
\hline & Cervical & 3 & 42.9 & 4 & 57.1 & 0.44 (0.09 to 2.05$)$ & 0.42 (0.08 to 2.21$)$ \\
\hline & Genitourinary & 19 & 61.3 & 12 & 38.7 & 0.93 (0.42 to 2.07$)$ & 0.95 (0.39 to 2.31$)$ \\
\hline & Gastrointestinal & 47 & 56.0 & 37 & 44.0 & 0.75 (0.43 to 1.29$)$ & 0.70 (0.36 to 1.36$)$ \\
\hline & Lung & 12 & 92.3 & 1 & 7.7 & $7.09(0.89 \text { to } 56.07)^{\star \star \star}$ & 7.61 (0.90 to 64.32$)$ \\
\hline & Lymphoma & 29 & 56.9 & 22 & 43.1 & 0.78 (0.40 to 1.48$)$ & 0.74 (0.34 to 1.63$)$ \\
\hline & Others & 41 & 50.6 & 40 & 49.4 & $0.60(0.35 \text { to } 1.04)^{\star \star \star}$ & 0.72 (0.38 to 1.34$)$ \\
\hline \multirow{5}{*}{$\begin{array}{l}\text { WHO stage of } \\
\text { cancer }\end{array}$} & I & 5 & 33.3 & 10 & 66.7 & 1 & 1 \\
\hline & II & 30 & 55.6 & 24 & 44.4 & $2.50(0.75 \text { to } 8.30)^{\star \star \star}$ & 2.87 (0.69 to 11.95$)$ \\
\hline & III & 102 & 62.0 & 71 & 38.0 & $2.87(0.94 \text { to } 8.76)^{\star \star \star}$ & $5.37(1.34 \text { to } 21.45)^{\star}$ \\
\hline & IV & 77 & 60.6 & 52 & 39.4 & $2.96(0.65 \text { to } 9.16)^{\star \star \star}$ & $4.55(1.12 \text { to } 18.44)^{\star}$ \\
\hline & Unknown & 30 & 53.5 & 14 & 46.5 & $4.28(1.23 \text { to } 14.91)^{\star \star \star}$ & 2.11 (0.49 to 8.95$)$ \\
\hline \multirow[t]{4}{*}{ Intensity of pain } & None & 32 & 66.7 & 16 & 33.3 & 1 & 1 \\
\hline & Mild & 36 & 62.1 & 22 & 37.9 & 0.81 (0.36 to 1.82$)$ & 0.76 (0.23 to 2.55$)$ \\
\hline & Moderate & 104 & 57.8 & 76 & 42.2 & 0.68 (0.35 to 1.33$)$ & 0.59 (0.16 to 2.12$)$ \\
\hline & Severe & 72 & 55.8 & 57 & 44.2 & $0.63(0.31 \text { to } 1.26)^{\star \star \star}$ & 0.54 (0.15 to 1.98$)$ \\
\hline \multirow{3}{*}{$\begin{array}{l}\text { Type of } \\
\text { treatment }\end{array}$} & Chemotherapy & 154 & 57.9 & 112 & 42.1 & 1 & 1 \\
\hline & Surgery & 11 & 73.3 & 4 & 26.7 & $2.00(0.62 \text { to } 6.44)^{\star \star \star}$ & $2.18(0.0 .58$ to 8.29$)$ \\
\hline & Combination & 79 & 59.0 & 55 & 41.0 & 1.04 (0.68 to 1.59$)$ & 1.01 (0.59 to 1.71$)$ \\
\hline \multirow{2}{*}{$\begin{array}{l}\text { Take } \\
\text { corticosteroid }\end{array}$} & Yes & 198 & 56.6 & 46 & 43.4 & 0.54 (0.30 to 0.96$)$ & $0.42(0.14$ to 1.21$)$ \\
\hline & No & 152 & 70.8 & 19 & 29.2 & 1 & 1 \\
\hline \multirow{2}{*}{$\begin{array}{l}\text { Comorbid } \\
\text { medical illness }\end{array}$} & Yes & 43 & 66.2 & 22 & 33.8 & 1.45 (0.83 to 2.53$)$ & 1.13 (0.59 to 2.16$)$ \\
\hline & No & 201 & 57.4 & 149 & 42.6 & 1 & 1 \\
\hline \multirow[t]{2}{*}{ Anxiety } & Yes & 154 & 54.2 & 95 & 45.8 & $1.37(0.92$ to 2.04$))^{\star \star \star}$ & 1.29 (0.83 to 2.03$)$ \\
\hline & No & 90 & 61.8 & 76 & 38.2 & 1 & 1 \\
\hline \multirow[t]{2}{*}{ Psychosis } & Yes & 149 & 53.1 & 87 & 46.9 & $1.51(1.02 \text { to } 2.24)^{\star \star \star}$ & $1.67(1.07 \text { to } 2.61)^{\star}$ \\
\hline & No & 95 & 63.1 & 84 & 36.9 & 1 & 1 \\
\hline \multirow[t]{2}{*}{ Malnutrition } & Yes & 185 & 52.7 & 118 & 47.3 & $0.71(0.45 \text { to } 1.09)^{\star \star \star}$ & 1.42 (0.81 to 2.47$)$ \\
\hline & No & 59 & 61.1 & 53 & 38.9 & 1 & 1 \\
\hline \multirow[t]{2}{*}{ Eating problem } & Yes & 236 & 36.4 & 157 & 63.6 & $2.63(1.07 \text { to } 6.41)^{\star \star \star}$ & $6.16(1.98 \text { to } 19.11)^{\star *}$ \\
\hline & No & 8 & 60.1 & 14 & 39.9 & 1 & 1 \\
\hline \multirow[t]{4}{*}{ BMI } & Underweight & 42 & 59.2 & 29 & 40.8 & $0.48(0.14 \text { to } 1.64)^{\star \star \star}$ & 0.63 (0.15 to 2.62$)$ \\
\hline & Normal weight & 162 & 57.4 & 120 & 42.6 & $0.45(0.14 \text { to } 1.43)^{\star \star \star}$ & $0.47(0.13$ to 1.75$)$ \\
\hline & Overweight & 28 & 60.9 & 18 & 39.1 & 0.51 (0.14 to 1.86$)$ & 0.52 (0.12 to 2.20$)$ \\
\hline & Obese & 12 & 75.0 & 4 & 25.0 & 1 & 1 \\
\hline
\end{tabular}

${ }^{*} \mathrm{P}<0.05 ;{ }^{* *} \mathrm{p}<0.01 ;{ }^{* \star *} \mathrm{p}<0.25$

AOR, adjusted OR; BMI, body mass index; COR, crude OR; HUCSH, Hawassa University Comprehensive Specialized Hospital. 
Table 4 Bivariate and multivariable regression analyses on anxiety symptoms and associated factors among patients with cancer at HUCSH, $2019(n=415)$

\begin{tabular}{|c|c|c|c|c|c|c|c|}
\hline \multirow[b]{3}{*}{ Variables } & \multirow[b]{3}{*}{ Category } & \multicolumn{4}{|c|}{ Anxiety symptoms } & \multirow[b]{3}{*}{ COR $(95 \% \mathrm{Cl})$} & \multirow[b]{3}{*}{ AOR $(95 \% \mathrm{Cl})$} \\
\hline & & \multicolumn{2}{|l|}{ Yes } & \multicolumn{2}{|l|}{ No } & & \\
\hline & & $\mathbf{N}$ & $\%$ & $\mathbf{N}$ & $\%$ & & \\
\hline \multirow{4}{*}{$\begin{array}{l}\text { Educational } \\
\text { status }\end{array}$} & Not able to read and write & 91 & 56.9 & 69 & 43.1 & $1.17(0.62 .2 .20)$ & 0.98 (0.48 to 1.99$)$ \\
\hline & Primary & 81 & 64.8 & 44 & 35.2 & $1.63(0.84 \text { to } 3.17)^{\star \star}$ & 1.31 (0.64 to 2.68) \\
\hline & Secondary & 50 & 63.3 & 29 & 36.7 & $1.53(0.75 \text { to } 3.13)^{\star \star}$ & 1.60 (0.73 to 3.46$)$ \\
\hline & College or above & 27 & 52.9 & 24 & 47.1 & 1 & 1 \\
\hline \multirow[t]{2}{*}{ Residence } & Urban & 177 & 62.8 & 105 & 37.2 & 1 & 1 \\
\hline & Rural & 72 & 54.1 & 61 & 45.9 & $0.70(0.46 \text { to } 1.06)^{\star \star}$ & 0.70 (0.43 to 1.12$)$ \\
\hline \multirow[t]{7}{*}{ Type of cancer } & Breast & 92 & 62.2 & 56 & 37.8 & 1 & 1 \\
\hline & Cervical & 4 & 57.1 & 3 & 42.9 & 0.81 (0.17 to 3.76$)$ & 0.69 (0.13 to 3.42$)$ \\
\hline & Genitourinary & 21 & 67.7 & 10 & 32.3 & 1.27 (0.56 to 2.91$)$ & $1.16(0.47$ to 2.84$)$ \\
\hline & Gastrointestinal & 42 & 50.0 & 42 & 50.0 & $0.60(0.35 \text { to } 1.04)^{\star \star}$ & 0.55 (0.30 to 1.02$)$ \\
\hline & Lung & 6 & 46.2 & 7 & 53.8 & 0.52 (0.16 to 1.63$)$ & 0.38 (0.11 to 1.29$)$ \\
\hline & Lymphoma & 36 & 70.6 & 15 & 29.4 & 1.46 (0.73 to 2.90$)$ & 1.37 (0.62 to 2.98$)$ \\
\hline & Others & 48 & 59.3 & 33 & 40.7 & 0.88 (0.50 to 1.54$)$ & $0.84(0.45$ to 1.56$)$ \\
\hline \multirow{5}{*}{$\begin{array}{l}\text { Stage of } \\
\text { cancer }\end{array}$} & I & 5 & 33.3 & 10 & 66.7 & 1 & 1 \\
\hline & ॥ & 33 & 61.1 & 21 & 38.9 & $3.14(0.94 \text { to } 10.48)^{\star \star}$ & $3.92(1.07 \text { to } 14.36)^{*}$ \\
\hline & III & 100 & 57.3 & 73 & 42.7 & $2.74(0.89 \text { to } 8.35)^{\star \star}$ & 3.29 (0.97 to 11.09$)$ \\
\hline & IV & 86 & 67.4 & 43 & 32.6 & $4.00(1.28 \text { to } 12.43)^{\star \star}$ & $5.04(1.44 \text { to } 17.59)^{\star}$ \\
\hline & Unknown & 25 & 55.8 & 19 & 44.2 & $2.36(0.77 \text { to } 8.98)^{\star \star}$ & 3.35 (0.89 to 12.63$)$ \\
\hline \multirow{2}{*}{$\begin{array}{l}\text { Take } \\
\text { corticosteroid }\end{array}$} & Yes & 215 & 61.4 & 31 & 38.6 & 1 & 1 \\
\hline & No & 135 & 52.3 & 34 & 47.7 & $0.68(0.40 \text { to } 1.17)^{\star \star}$ & 0.66 (0.33 to 1.31$)$ \\
\hline \multirow[t]{2}{*}{ Medical illness } & Yes & 33 & 50.8 & 32 & 49.2 & $0.64(0.37 \text { to } 1.08)^{\star \star}$ & 0.61 (0.33 to 1.11$)$ \\
\hline & No & 216 & 61.7 & 134 & 38.3 & 1 & 1 \\
\hline \multirow[t]{3}{*}{ Social support } & Poor & 77 & 62.1 & 47 & 37.9 & $1.44(0.84 \text { to } 2.48)^{\star \star}$ & 1.68 (0.90 to 3.13$)$ \\
\hline & Moderate & 121 & 62.1 & 74 & 37.9 & $1.44(0.88 \text { to } 2.36)^{\star \star}$ & 1.52 (0.89 to 2.62$)$ \\
\hline & Strong & 51 & 53.1 & 45 & 46.9 & 1 & 1 \\
\hline \multirow[t]{2}{*}{ Depression } & Yes & 95 & 55.6 & 76 & 44.4 & $1.36(0.91 \text { to } 2.03)^{\star \star}$ & 1.34 (0.86 to 2.09 ) \\
\hline & No & 154 & 63.1 & 90 & 36.9 & 1 & 1 \\
\hline \multirow[t]{2}{*}{ Psychosis } & Yes & 152 & 54.2 & 84 & 45.8 & $1.53(1.02 \text { to } 2.27)^{\star \star}$ & $1.73(1.12 \text { to } 2.66)^{\star}$ \\
\hline & No & 97 & 64.4 & 82 & 35.6 & 1 & 1 \\
\hline \multirow[t]{3}{*}{ Age (years) } & $<30$ & 58 & 65.9 & 30 & 34.1 & 1 & 1 \\
\hline & $31-50$ & 132 & 57.6 & 97 & 42.4 & $0.70(0.42 \text { to } 1.17)^{\star \star}$ & 0.87 (0.49 to 1.54$)$ \\
\hline & $>50$ & 59 & 60.2 & 39 & 39.8 & 0.78 (0.43 to 1.42$)$ & 1.12 (0.55 to 2.29$)$ \\
\hline \multirow{2}{*}{$\begin{array}{l}\text { Eating } \\
\text { problem }\end{array}$} & Yes & 239 & 45.5 & 154 & 54.5 & $1.86(0.78 \text { to } 4.41)^{\star \star}$ & 1.92 (0.73 to 5.00$)$ \\
\hline & No & 10 & 60.8 & 12 & 39.2 & 1 & 1 \\
\hline
\end{tabular}

${ }^{*} \mathrm{P}<0.05 ;{ }^{* *} \mathrm{P}<0.25$.

AOR, adjusted OR; COR, crude OR; HUCSH, Hawassa University Comprehensive Specialized Hospital.

an impact on the magnitude of depression or anxiety in this study. This is the first study of its kind in Ethiopia and one of the very few in Africa. Therefore, the study is an important contribution to our knowledge regarding the potential role of depression and anxiety in the treatment of cancer in this area.

\section{CONCLUSIONS}

The prevalence of depression and anxiety symptoms among patients with cancer was considerably high. Occupation, cancer stage, comorbid psychotic symptoms, eating problem in the past 2 weeks and patients' age were independent factors of depression symptoms 
among patients with cancer. In addition, cancer stage and comorbid psychosis were associated with anxiety symptoms. Perhaps more attention is needed to detect changes in the psychological status of patients with cancer in an effort to reduce the occurrence of depression and anxiety. Continuous screening for symptoms of anxiety and depression is recommended as a necessary approach for good cancer care; on the other hand, after the diagnosis of clinically important psychological disorders, proper treatment interventions must be performed to improve the quality of life of these patients. Also, special attention should be given for patients with cancer with the mentioned risk factors of depression and anxiety.

\section{Author affiliations}

${ }^{1}$ School of Nursing, Hawassa University College of Medicine and Health Sciences, Hawassa, Ethiopia

${ }^{2}$ Curtin School of Population Health, Curtin University, Bentley, Perth, Australia ${ }^{3}$ School of Public Health, Hawassa University College of Medicine and Health Sciences, Hawassa, Ethiopia

${ }^{4}$ Faculty of Medicine, Hawassa University College of Medicine and Health Sciences, Hawassa, Ethiopia

${ }^{5}$ Environmental Health, Hawassa University College of Medicine and Health Sciences, Hawassa, Ethiopia

${ }^{6}$ Australian Centre for Public and Population Health Research, School of Public Health, Faculty of Health, University of Technology Sydney, Ultimo, New South Wales, Australia

Acknowledgements We would like to acknowledge Hawassa University, staff of HUCSH, data collectors and participants for their valuable participation in the study process.

Contributors MA, BDe, BDu, DG, NB, LG, AG and AB were involved in the design and data collection of the study. MA and BDe performed the analysis and write-up of the study. MA prepared the manuscript for publication and all authors critically reviewed the manuscript. MA is responsible for the overall content as guarantor. All authors read and approved the final manuscript.

Funding The authors have not declared a specific grant for this research from any funding agency in the public, commercial or not-for-profit sectors.

\section{Competing interests None declared.}

Patient and public involvement Patients and/or the public were not involved in the design, or conduct, or reporting, or dissemination plans of this research.

\section{Patient consent for publication Not required.}

Ethics approval This study was approved by the Institutional Review Board at the College of Medicine and Health Sciences of Hawassa University (No. IRB/047/11, on 26 February 2019). Permission was also obtained from administrative bodies at HUCSH. Patients were enrolled into the study on a voluntary basis after a thorough explanation about the study. They were informed and obtained verbal consent and interviewed during their visits to the cancer treatment centre. Any information obtained from the patients was kept confidential.

Provenance and peer review Not commissioned; externally peer reviewed.

Data availability statement All data relevant to the study are included in the article. All the datasets used and analysed during the current study are available in this manuscript.

Open access This is an open access article distributed in accordance with the Creative Commons Attribution Non Commercial (CC BY-NC 4.0) license, which permits others to distribute, remix, adapt, build upon this work non-commercially, and license their derivative works on different terms, provided the original work is properly cited, appropriate credit is given, any changes made indicated, and the use is non-commercial. See: http://creativecommons.org/licenses/by-nc/4.0/.

\section{ORCID iDs}

Mohammed Ayalew http://orcid.org/0000-0001-9973-5741

Bereket Duko http://orcid.org/0000-0002-4419-0016

Asres Bedaso http://orcid.org/0000-0001-7859-0264
REFERENCES

1 WHO. WHO. Cancer fact sheet [Internet]. WHO, 2017. www.who.int/ mediacentre/\%0Afactsheets/fs297/en/

2 World Health Organization (WHO). Latest global cancer data : Cancer burden rises to 18.1 million new cases and 9. 6 million cancer deaths in 2018. Int Agency Res Cancer, 2018: 13-15.

3 Ferlay J, Ervik M, Lam F. Global cancer Observatory: cancer today. Lyon: Int Agency Res Cancer, 2020.

4 Zhu J, Fang F, Sjölander A, et al. First-onset mental disorders after cancer diagnosis and cancer-specific mortality: a nationwide cohort study. Ann Oncol 2017;28:1964-9.

5 Walker J, Holm Hansen C, Martin P, et al. Prevalence of depression in adults with cancer: a systematic review. Ann Oncol 2013;24:895-900.

6 Carroll BT, Kathol RG, Noyes R, et al. Screening for depression and anxiety in cancer patients using the hospital anxiety and depression scale. Gen Hosp Psychiatry 1993;15:69-74.

7 Ali S, Stone MA, Peters JL, et al. The prevalence of co-morbid depression in adults with type 2 diabetes: a systematic review and meta-analysis. Diabet Med 2006;23:1165-73.

8 Die Trill M. Anxiety and sleep disorders in cancer patients. EJC Suppl 2013;11:216-24.

9 Breitbart W. Identifying patients at risk for, and treatment of major psychiatric complications of cancer. Support Care Cancer 1995;3:45-60.

10 Yang Y-L, Liu L, Wang Y, et al. The prevalence of depression and anxiety among Chinese adults with cancer: a systematic review and meta-analysis. BMC Cancer 2013;13:393.

11 Donovan KA, Thompson LMA, Jacobsen PB. Pain, Depression, and Anxiety in Cancer. In: Handbook of pain and palliative care: Biobehavioral approaches for the life course, 2012: 615-37.

12 Pitman A, Suleman S, Hyde N, et al. Depression and anxiety in patients with cancer. BMJ 2018;361:k1415.

13 Bodurka-Bevers D, Basen-Engquist K, Carmack CL, et al. Depression, anxiety, and quality of life in patients with epithelial ovarian cancer. Gynecol Oncol 2000;78:302-8.

14 Meyer HAM, Sinnott C, Seed PT. Depressive symptoms in advanced cancer. Part 2. depression over time; the role of the palliative care professional. Palliat Med 2003;17:604-7.

15 Warmenhoven F, van Rijswijk E, van Weel C, et al. Low prevalence of depressive disorder in ambulatory advanced cancer patients using the schedules for clinical assessment in neuropsychiatry (scan 2.1). J Affect Disord 2012;136:1209-11.

16 Lloyd-Williams M, Friedman T. Depression in palliative care patients-a prospective study. Eur J Cancer Care 2001;10:270-4.

17 Walker J, Hansen CH, Martin P, et al. Prevalence, associations, and adequacy of treatment of major depression in patients with cancer: a cross-sectional analysis of routinely collected clinical data. Lancet Psychiatry 2014;1:343-50.

18 Satin JR, Linden W, Phillips MJ. Depression as a predictor of disease progression and mortality in cancer patients. Cancer 2009;115:5349-61.

19 Pinquart M, Duberstein PR. Depression and cancer mortality: a meta-analysis. Psychol Med 2010;40:1797-810.

20 Smith HR. Depression in cancer patients: pathogenesis, implications and treatment (review). Oncol Lett 2015;9:1509-14.

21 Yousaf U, Christensen M-L, Engholm G, et al. Suicides among Danish cancer patients 1971-1999. Br J Cancer 2005;92:995-1000.

22 Colleoni M, Mandala M, Peruzzotti G, et al. Depression and degree of acceptance of adjuvant cytotoxic drugs. Lancet 2000;356:1326-7.

23 Chochinov HM. Depression in cancer patients. Lancet Oncol 2001;2:499-505.

24 Sharpe M, Strong V, Allen K, et al. Major depression in outpatients attending a regional cancer centre: screening and unmet treatment needs. Br J Cancer 2004;90:314-20.

25 Carlsen K, Jensen AB, Jacobsen E, et al. Psychosocial aspects of lung cancer. Lung Cancer 2005;47:293-300.

26 Block SD. Assessing and managing depression in the terminally ill patient. ACP-ASIM End-of-Life Care Consensus Panel. American College of Physicians - American Society of Internal Medicine. Ann Intern Med 2000;132:209-18.

27 Uwayezu MG, Gishoma D, Sego R, et al. Anxiety and depression among cancer patients: prevalence and associated factors at a Rwandan referral hospital. Rwanda J Med Heal Sci 2019;2:118-25.

28 Niedzwiedz CL, Knifton L, Robb KA, et al. Depression and anxiety among people living with and beyond cancer: a growing clinical and research priority. BMC Cancer 2019;19:1-8.

29 Zigmond AS, Snaith RP. The hospital anxiety and depression scale. Acta Psychiatr Scand 1983;67:361-70.

30 Bjelland I, Dahl AA, Haug TT, et al. The validity of the hospital anxiety and depression scale. An updated literature review. J Psychosom Res 2002;52:69-78. 
31 Whelan-Goodinson R, Ponsford J, Schönberger M. Validity of the hospital anxiety and depression scale to assess depression and anxiety following traumatic brain injury as compared with the structured clinical interview for DSM-IV. J Affect Disord 2009;114:94-102.

32 Gao LP WC. Influencing factors of quality of life in cancer patients of initial stages receiving radio- and chemotherapy and its countermeasures. Nurs J Chin People's Lib Army 2008;8:10-12.

33 Bebbington $\mathrm{P}$. The psychosis screening questionnaire. Int $\mathrm{J}$ Methods Psychiatr Res 1995;5:11-19.

34 Johns LC, Cannon M, Singleton N, et al. Prevalence and correlates of self-reported psychotic symptoms in the British population. $\mathrm{Br} \mathrm{J}$ Psychiatry 2004;185:298-305.

35 Osman A, Bagge CL, Gutierrez PM, et al. The suicidal behaviors Questionnaire-Revised (SBQ-R): validation with clinical and nonclinical samples. Assessment 2001;8:443-54.

36 Bøen H, Dalgard OS, Bjertness E. The importance of social support in the associations between psychological distress and somatic health problems and socio-economic factors among older adults living at home: a cross sectional study. BMC Geriatr 2012;12:1-12.

37 El RC, Zaghloul H JJRM. Pain assessment practices in patients with cancer admitted to the oncology floor. J Hematol Oncol Pharm 2017:7:109-13

38 Dugashvili G, Van den Berghe L, Menabde G, et al. Use of the universal pain assessment tool for evaluating pain associated with TMD in youngsters with an intellectual disability. Med Oral Patol Oral Cir Bucal 2017;22:89-94.

39 Kaiser MJ, Bauer JM, Ramsch C, et al. Validation of the mini nutritional assessment short-form (MNA®-SF): a practical tool for identification of nutritional status. J Nutr Health Aging 2009;13:782-8.

40 Sobieski D, Professions H, Amella EJ. Assessing nutrition in older adults. Hartford insT Geriatr nursing, New York Univ Rory Meyers coll Nurs 2019.

41 Berihun F, Haile S, Abawa M. Archives of depression and anxiety prevalence and correlates of anxiety and depression among cancer patients in the University of Gondar comprehensive specialized Hospital, Northwest Ethiopia. Arch Depress Anxiety 2017;3:42-8.

42 Dogar IA A, Waqar M, Kiran M. Depression and anxiety in cancer patients in outpatient department of a tertiary care hospital in Pakistan. Pak J Med Sci 2009;25:734-7.

43 Wondie Y, Mehnert A, Hinz A. The hospital anxiety and depression scale (HADS) applied to Ethiopian cancer patients. PLoS One 2020;15:e0243357.

44 Hong JS, Tian J. Prevalence of anxiety and depression and their risk factors in Chinese cancer patients. Support Care Cancer 2014;22:453-9.

45 Naser AY, Hameed AN, Mustafa N, et al. Depression and anxiety in patients with cancer: a cross-sectional study. Front Psychol 2021:12:585534.

46 Yan X, Chen X, Li M, et al. Prevalence and risk factors of anxiety and depression in Chinese patients with lung cancer : a cross-sectional study. Cancer Manag Res 2019;11:4347-56.

47 Hashemi S-M, Hormozi M, Allahyari A, et al. The prevalence of depression, anxiety, and stress in patients with breast cancer in
Southeast Iran in 2019: a cross-sectional study. Oncol Clin Pract 2019;16:104-8.

48 Elghazali Bakhiet T, Ali SM, Bakhiet AM. Prevalence of depression and anxiety among adult patients undergoing chemotherapy in Khartoum, Sudan: a cross-sectional study. J Affect Disord Rep 2021;6:100218

49 Chen X, Lu W, Zheng Y, et al. Exercise, tea consumption, and depression among breast cancer survivors. J Clin Oncol 2010;28:991-8.

50 Nikbakhsh N, Moudi S, Abbasian SKS. Prevalence of depression and anxiety among cancer patients. Casp J Intern Med 2014;5:167-70.

51 Kim S-S, Muntaner C, Kim H, et al. Gain of employment and depressive symptoms among previously unemployed workers: a longitudinal cohort study in South Korea. Am J Ind Med 2013;56:1245-50.

52 Ell K, Xie B, Wells A, et al. Economic stress among lowincome women with cancer: effects on quality of life. Cancer 2008;112:616-22.

53 Smith T, Stein KD, Mehta CC, et al. The rationale, design, and implementation of the American cancer Society's studies of cancer survivors. Cancer 2007;109:1-12.

54 Taskila T, Lindbohm ML. Factors affecting cancer survivors employment and work ability. Acta Oncol 2007;46:446-51.

55 Passik SD, Dugan W, McDonald MV, et al. Oncologists' recognition of depression in their patients with cancer. J Clin Oncol 1998;16:1594-600.

56 Wong-Kim EC, Bloom JR. Depression experienced by young women newly diagnosed with breast cancer. Psychooncology 2005;14:564-73.

57 Buckley PF, Miller BJ, Lehrer DS, et al. Psychiatric comorbidities and schizophrenia. Schizophr Bull 2009;35:383-402.

58 Krabbendam L, Myin-Germeys I, Bak M, et al. Explaining transitions over the hypothesized psychosis continuum. Aust N Z J Psychiatry 2005;39:180-6.

59 van Rossum I, Dominguez M-de-G, Lieb R, et al. Affective dysregulation and reality distortion: a 10-year prospective study of their association and clinical relevance. Schizophr Bull 2011:37:561-71.

60 Verdoux H, van Os J, Maurice-Tison S, et al. Increased occurrence of depression in psychosis-prone subjects: a follow-up study in primary care settings. Compr Psychiatry 1999;40:462-8.

61 Patten SB, Neutel Cl. Corticosteroid-Induced adverse psychiatric effects: incidence, diagnosis and management. Drug Saf 2000;22:111-22.

62 van Dam FS, Schagen SB, Muller MJ, et al. Impairment of cognitive function in women receiving adjuvant treatment for high-risk breast cancer: high-dose versus standard-dose chemotherapy. J Natl Cancer Inst 1998;90:210-8.

63 Huppert JD, Smith TE. Anxiety and schizophrenia: the interaction of subtypes of anxiety and psychotic symptoms. CNS Spectr 2005;10:721-31.

64 Olfson M, Lewis-Fernández R, Weissman MM, et al. Psychotic symptoms in an urban general medicine practice. Am J Psychiatry 2002;159:1412-9. 